and two related to relief. Firstly, good information should be given to parents, schools, and children and should include the dangers of cannabis (memory impairment, the fact that it contains more carcinogens than tobacco, etc). Secondly, drugs should be eliminated. The police are on the right track in the way that they tackle big dealers, but they should be allowed to tackle street dealing as well, because it is difficult to find drugs when petty sales are reduced. ${ }^{5}$ Thirdly, users should be able to gain admission to drug free institution where they are treated with respect and encouragement so that they can regain their self respect. Finally, good aftercare is necessary: any forme user should have a counsellor, who could help him or her find accommodation and a job. Weekly urine checks are advisable so that any relapse can be recognised.

KF GUNNING
President, Dutch National Board of Drug Prevention Groene Wetering 24,

3062 PC Rotterdam,

3062 PC Rotterd
Netherlands

1 Smith R. The war on drugs. BMf 1995;311:1655-6. (2330 December.)

2 Het Nederlandse drugbeleid [The Dutch drug policy]. The Hague: Staatsdrukkerii en Uitgeverij, 1995. (24077 No 2.)

3 Dezwart WM, Mensink C. Alcohol, tabak, drugs en gokken in cijfers. Utrecht, NIAD, 1993.

4 Moll $\mathrm{H}$. Meer jonge verslaafden door goedkope heroine [More young addicts through cheap heroin]. NRC Handelsblad 1992 Jul 2 .

5 Swedish National Institute of Public Health. $A$ restrictive drug policy: the Swedish experience. Stockholm: SNIPH, 1993.

\section{Evaluating new surgical procedures}

\section{Hip replacements come in at least $10^{11}$ varieties}

EDITOR,-I strongly support Ian Russell's call for collaboration between surgeons and trialists.' Russell makes many important points, but three additional questions should also be asked when surgical procedures are being evaluated: which?, how?, and when? These are particularly relevant to surgery for trauma and in orthopaedics. An example is total hip replacement operations. Not all such procedures are the same; there is no practised consensus on hardware or method. ${ }^{2}$

Which?-At least 62 different total hip replacements are available in Britain. ${ }^{3}$ Many are modular, permitting the use of different sizes of femoral head with different materials at the surgeon's discretion, which allows further multiple variation.

How?-In the past six years I have worked for 17 consultant orthopaedic surgeons, who have all used a different, unique method for total hip replacement operations. The table shows the number of possible variations at various stages that I have learnt. The sum of the variations is $1.08 \times 10^{11}$. This is a conservative, theoretical estimate of the number of possible methods in total hip replacement operations. Each variation at each stage could alter the final outcome.

When?-A good result at five years does not always mean a good result at 20 years. The randomised controlled trial in surgery is the utopian ideal that will provide evidence based surgery. This is the goal to which all surgeons should strive, though the challenge is enormous.

DEREK J PEGG Senior registrar, orthopaedic surgery

Royal Manchester Children's Hospital,

Pendlebury,

Manchester M27 4HA

1 Russell I. Evaluating new surgical procedures. $B M \mathcal{F} 1995 ; 311$ : 1243-4. (11 November.)

2 Hashemi-Nejad A, Goddard NJ, Birch NC. Current attitudes to cementing techniques in British hip surgery. Ann R Coll Surg Engl 1994;76:396-400.

3 Murray DW, Carr AJ, Bulstrode CJ. Which primary total hip replacement? F Bone foint Surg [Br] 1995;77:520-7.

\section{Design of trials should depend on whether new skills are required}

EdrToR,-We agree with Ian Russell' that the randomised trial is the design of choice for evaluating surgical procedures; this view has been reinforced by others. ${ }^{2}$ Nevertheless, new surgical procedures should be studied in the context of the skills required to achieve them. If a new procedure requires the acquisition of new skills then the learning curve ought to be assessed. On the other hand, if the procedure is conceptually a new approach to a disease but requires traditional surgical skills then experienced surgeons ought to perform it; then it should be possible to randomise the first patient who undergoes the new procedure. Once a technique has been established as safe and effective and its widespread impact and efficacy are being studied it may be widely disseminated, but compulsory audit is essential.

Russell deems the blinding of patients and carers in randomised controlled trials to be irrelevant and impractical. If media publicity has imbued the minds of patients and carers with the advantages or dangers ${ }^{4}$ of a new operation then blinding becomes highly relevant. In practice, blinding patients and carers is not as difficult as people might think (AWM et al, annual conference, Harrogate, 20-22 April 1994). The use of multiple centres in such trials also needs to be carefully considered because, although recruitment is facilitated, the trials necessarily become loosely controlled.

A W MAJEED
Lecturer in surgery $\begin{array}{r}\text { A G JOHNSON } \\ \text { Professor of surgery }\end{array}$

Department of Surgical and Anaesthetic Sciences,

Royal Hampshire Hospital,

Sheffield S10 2JF

1 Russell I. Evaluating new surgical procedures. BMF 1995;311 1243-4. (11 November.)

2 Williams MH, Blazeby JM, Eachus II. Outcome measurement in surgical practice. Ann R Coll Surg Engl 1995;77:401-3.

Kingman S. Simple way to lose a stone. Independent on Sunday 2 Jun 1991.

4 Altman LK. Surgical injuries lead to new rule. New York Times 14 Jun 1992.

\section{Few trials of laparoscopic cholecystectomy} have been randomised

EDrToR,-We agree with Ian Russell that the randomised trial is the design of choice for evaluating new surgical procedures. ${ }^{1}$ Russell points out

Table 1-Possible options in total hip replacement surgery

\begin{tabular}{lc|lc}
\hline Stage of procedure & Possible variations & Stage of procedure & Possible variations \\
\hline Theatre environment & 3 & Acetabular preparation & 6 \\
Patient's position & 3 & Acetabular cementing technique & 3 \\
Skin preparation & 4 & Femoral preparation & 8 \\
Patient draping & 6 & Distal cement plug & 2 \\
Surgeon's gown & 9 & Femoral cementing technique & 4 \\
Skin drape & 3 & Closure & 2 \\
Towels & 2 & Antibiotic prophylaxis & 3 \\
Approach & 7 & Thromboembolic prophylaxis: & 4 \\
Tray system & 2 & Chemical & 4 \\
Power instruments & 2 & Physical & \\
Irrigation & 3 & & \\
\hline
\end{tabular}

\title{
Treatment of acute anaphylaxis
}

\section{Letters contained errors of logic}

Edrror,-The letters ${ }^{1}$ about my article on acute anaphylaxis ${ }^{2}$ show the difficulties of trying to provide simple algorithms when controlled trials are impossible and the pattern of symptoms and severity vary. Some of the replies contain errors of logic.

Glenis K Scadding emphasises the use of tourniquets to avoid further contact with the allergen. Such use is not supported by data and may be hazardous as release of arterial tourniquets pro- 
duces reactive hyperaemia, and catastrophic release of antigen into the circulation may occur. If further exposure to antigen is harmful during established anaphylaxis (which is not always the case) a tourniquet may be harmful. The compression bandage technique used in first aid for envenomation, ${ }^{3}$ which localises venom, does not damage tissue, and does not lead to deterioration on removal may be more suitable.

Jonathan O'B Hourihane and John O Warner emphasise that in patients with previous reactions the history is crucial, not of "little value." I stated that "the history is of vital importance." But attributing the cause of anaphylaxis to drugs on the basis of previous exposure is not valid and has led to fatal second reactions. I note that these authors regard laryngeal oedema as life threatening, whereas L C Luke does not.

$\mathbf{R}$ Alexander and colleagues (in contrast to Luke) suggest that anaphylaxis should always be treated with intravenous adrenaline. This is nonsense. The efficacy of early subcutaneous or intramuscular adrenaline is evident in those who self administer it. When venous access is not obtainable in adults or children other routes are satisfactory. Ventricular arrhythmias are more likely with intravenous use, and in the absence of electrocardiographic monitoring hypotension due to arrhythmias may not be detected and more adrenaline may be given. I do not, as John Clear and colleagues say I do, advocate withholding adrenaline until monitoring is in place. If there is no electrocardiographic monitoring, intramuscular adrenaline is safer for the reason given above and the added risk of infarction and cerebral haemorrhage.

Alexander and colleagues further advocate intraosseous injection in children and nebulised adrenaline. There is no evidence that either is more effective than intramuscular injection (including in the reference cited), and both techniques have practical difficulties. The authors' advocacy of halothane rather than isoflurane is illogical Halothane is getting hard to find, has not been shown to be superior to isoflurane, and increases the risk of ventricular arrhythmias with adrenaline.

MALCOLM FISHER

Royal North Shore Hospital

St Leonards,

NSW,

Australia

1 Treatment of acute anaphylaxis [letters]. BMF 1995;311:1434-6. (25 November.)

2 Fisher M. Treatment of acute anaphylaxis. BMF 1995;311: 731-3. (16 September.)

3 Sutherland SK, Coulter AR, Harris RD. Rationalisation of first aid measures for elapid snakebite. Lancet 1979;ii:183-6.

\section{Patients should be taught how to inject adrenaline}

EDrToR,-Although no clear consensus has yet emerged about the place of adrenaline injections in the treatment of children with acute allergy, ${ }^{1}$ it is incontrovertible that families must be shown how to use any device that is prescribed. In the past two months 12 children have been referred to our clinic with presumed allergy to peanuts. Eight had already been prescribed adrenaline (Min-I-Jet (three) or Epipen (five)), but only one family had received any training. In six cases neither a parent nor the child had been shown; in the remaining case the child but not the parents had been instructed.

Doctors have a responsibility to ensure that patients know how and when to take any medicine prescribed. This does not usually present a problem when medicines are taken by mouth (although timing and the relation to food can be important). For drugs given by injection-particularly a dangerous drug like adrenaline-it is plainly inadequate to issue a prescription with no demon- stration. Further training is needed before a child comes to harm.

HUGH DAVIES Consultant paediatrician JULIE HARRIS Allergy nurse specialist ABBAS KAKOO

Paediatric Allergy Clinic Paediatric senior registrar St Mary's Hospital London W2 1NY

1 Treatment of acute anaphylaxis [letters]. BMF 1995;311:1434-6. (25 November.)

\section{"Jumping beans" are almost identical with medicines}

EDITOR,-The ingestion of medicines by young children is an important problem in Britain and leads to many of them attending accident and emergency departments and needing admission to hospital. Six to 10 deaths each year in children aged under 10 are due to poisoning by medicinal agents. ${ }^{1}$

Recently, "jumping beans," which can be bought from local shops, were distributed to children aged 4 to 6 at a party. The capsule of each "bean" dissolves easily in water and releases a $5 \mathrm{~mm}$ ball bearing; the lower row in figure 1 shows the beans and the ball bearing. The upper row in the figure shows the orange-white capsules of phenytoin (100 mg) and the magenta-yellow capsules of amoxycillin $(500 \mathrm{mg})$.

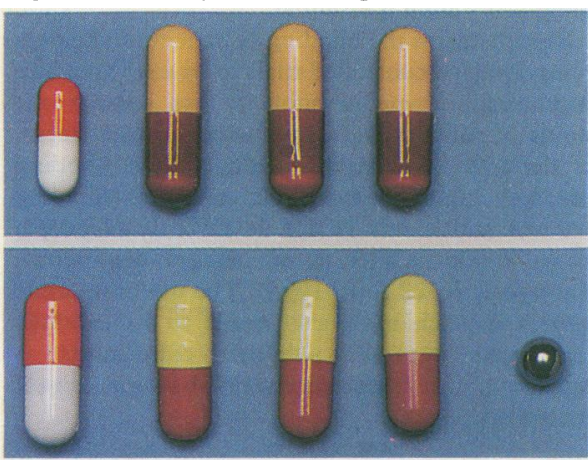

Fig 1-Capsules of phenytoin and amoxycillin (top) and "jumping beans" and ball bearing (bottom)

The prevention of accidents due to the ingestion of medicines primarily requires the education of both parents and children, and it is therefore inappropriate that toys that clearly contradict guidelines are readily available. The message from these "beans" is that playing with "medicines" is acceptable; this is one of the follies of commerce.

MARTIN HEWITT

Queen's Medical Centre

Consultant

Queen's Medical Centre

Nottingham NG7 2UH

1 Office of Population Censuses and Surveys. Mortality statistics: childhood. London: OPCS Surveys, 1993.

\section{Women doctors' use of hormone replacement therapy}

\section{High prevalence of use is not confined to doctors}

EDITOR,-A J Isaacs and colleagues report high rates of use of hormone replacement therapy among a sample of women doctors. ${ }^{1}$ They note the relative paucity of information regarding the prevalence of use and remark that this high rate among female doctors may "presage more widespread use in the general population."
We carried out a survey of use of hormone replacement therapy among women attending the Oxfordshire NHS breast screening programme between November 1994 and November 1995 Women aged 50-64 who are registered with a general practitioner are routinely invited to attend for screening. A random sample of 2291 women were sent a self administered questionnaire with their invitation to attend for screening and were asked to bring the completed questionnaire with them to their screening appointment. Altogether $1707(75 \%)$ of the women invited for screening attended and $1388(81 \%)$ of these completed the questionnaire. Overall, 591 of the 1388 respondents ( $43 \%$ ) had ever used hormone replacement therapy; 409 were using it currently and 200 had used it for five or more years. Table 1 shows the proportions of current and ever users by age for women aged 50-64. The prevalence of current use fell greatly with age, from $38 \%$ at age $50-54$ to $17 \%$ at age 60-64. A significant trend with age was apparent for ever use.

Table 1-Prevalence of use of hormone replacement therapy by age in women attending for breast screening in Oxfordshire (figures are percentages (numbers) *

\begin{tabular}{lll}
\hline & Current uset & Ever use‡ \\
\hline Age group (years): & & \\
$50-$ & $38(194 / 504)$ & $51(258 / 504)$ \\
$55-$ & $31(120 / 388)$ & $46(180 / 388)$ \\
$60-64$ & $17(61 / 361)$ & $28(102 / 361)$ \\
\hline
\end{tabular}

* 86 Women were aged $<50$ or $>64$ at screening; 49 values were missing.

for trend: $t \chi^{2}=45.68(1 \mathrm{df}), P<0.00001 ; \ddagger \chi^{2}=42.76(1 \mathrm{df})$, $P<0.00001$

Oxfordshire may not be representative of Britain as a whole, and women participating in breast screening are of higher social class and are generally more health conscious than those who decline screening. ${ }^{2}$ Nevertheless, this population based study provides evidence that the use of hormone replacement therapy is more widespread than previously reported and suggests that a high prevalence of use is not confined to female doctors.

EMILY BANKS Clinical research fellow BARBARA CROSSLEY Research officer

Imperial Cancer Research Fund, Cancer Epidemiology Unit, Radcliffe Infirmary, Oxford OX2 6HE

RUTH ENGLISH

Breast Care Unit,

Oxford Radcliffe NHS Trust,

Oxford OX3 7JH

Consultant radiologist

ANN RICHARDSON

Department of Public Health and General Practice,

Christchurch School of Medicine,

New Zealand

1 Isaacs AJ, Britton AR, McPherson K. Utilisation of hormone replacement therapy by women doctors. $B M 7$ 1995;311: 1399-401. (25 November)

2 Alexander FE, Anderson TJ, Brown HK, Forrest APM Hepburn W, Kirkpatrick AE, et al. The Edinburgh randomised trial of breast cancer screening: results after 10 years of mised trial of breast cancer screening:

\section{May be to enable them to cope with demands of their job}

EDrToR,-A J Isaacs and colleagues suggest that women doctors have a relatively high rate of use of hormone replacement therapy. ${ }^{1}$ Women doctors do seem to be ahead of an increasing trend for women to take such therapy, but they are perhaps not as far ahead as the authors' review of the literature indicates.

A study of use of hormone replacement therapy 